\title{
Measuring customer experience in situ: The link between appraisals, emotions and overall assessments
}

\begin{abstract}
Customer experience is frequently researched using one-off recall studies, missing the opportunity to assess the momentary fluctuations associated with consumption in real time. To address this gap, this study investigates how specific experience appraisals of an event affect emotions at different points in time, as well as determining how these appraisals contribute to overall satisfaction, recommendation, and repeat visitation. Fiftyone event goers report their experiences on four occasions (three during and one post event). Results show appraisals of having fun predict feelings of joy at each of the three sampling periods, whereas appraisals of sensory experience predict feelings of inspiration. Overall, sensory appraisals at Time-2 and appraisals of fun at Time-3 are associated with higher ratings of recommendation and repeat visitation. This research extends the understanding of customer experience by demonstrating the differential role of appraisals and emotions in real time and the flow-on effects to post experience assessments.
\end{abstract}

Keywords: Customer experience; experience-based sampling; appraisals; emotions; satisfaction; intention to recommend; intention for repeat visit. 


\section{Introduction}

Customer experience is the internal and subjective response a person has when encountering a company’s offerings (Meyer \& Schwager, 2007) and is a major factor for service industries’ success, with strong links to important variables such as satisfaction and loyalty (Hosany \& Witham, 2009). Customer experience is complex in nature, as it depends on the individual, the situation, and the service offerings. Experiences are also likely to be varied, with multiple benefits (e.g., Verleye, 2015). Some customer experience benefits are cognitive in nature, such as discovering new things or learning new knowledge, whereas other experiences are more hedonic, such as having fun, and still others are more sensory or social in orientation. The expected benefits from an individual's experience may differ markedly depending on the consumption situation. For example, benefits of a cognitive kind are more likely to be sought in a situation such as attending a seminar, whereas hedonic benefits are more likely sought when catching up with friends at a bar.

Appraisal theory (e.g., Roseman, Spindel, \& Jose, 1990; Smith \& Ellsworth, 1985) proposes that customers' appraisals of their experiences are highly subjective and likely to be based on the match between the type of experiences the individual expects, their goals, and what the individual encounters in a natural consumption context (hereafter referred to as in situ) (Hormuth, 1986). Within appraisal theory, this match is known as goal congruence (Roseman et al., 1990). Furthermore, appraisal theory proposes that customers' appraisals are the determinants of different emotional experiences and explain, for example, why two individuals with different appraisals of the same event will have different emotional responses (Roseman et al., 1990). Importantly, customers’ 
appraisals of their experiences are also likely to be correlated with overall assessments, such as satisfaction and loyalty (e.g., Mosteller, Donthu, \& Eroglu, 2014; Soscia, 2007). In addition, individuals' positive or negative emotions have been found to change throughout the experience journey (e.g., Lin, Kerstetter, Nawijn, \& Mitas, 2014). However, the literature contains few empirical studies investigating customer appraisals and emotions at different points in the customer's journey.

To provide empirical evidence on the relationship between customer appraisals and emotions in real time and fill in the gap in customer experience research, the current study employs an experience-based sampling method to examine the association between appraisals and emotions during the attendance at a food and wine event, as well as a postexperience overall assessment of satisfaction, intention to recommend, and intention to make a repeat visit. The overarching research questions guiding this study are: (1) What is the relationship between appraisals of experience dimensions and associated emotional responses across time? (2) Do appraisals of experience dimensions across time contribute to variance in satisfaction, recommendation, and/or repeat visitation? (3) How do emotions customers feel at an event vary across time?

This research makes the following contributions. First, the study draws on the principles of appraisal theory, to empirically examine the relationship between appraisals and associated emotional responses. Second, by using experience-based sampling, the study captures fluctuations in customers' appraisals and emotions across time so as to provide new insights into people’s lived experiences at a level that is more micro and momentary level than is common in past research. Third, by adopting a broad perspective, this study investigates the relationship between appraisals and overall 
evaluation variables. Finally, the research demonstrates how the use of apps presents a reliable, user-friendly, cost-effective, and efficient solution for data collection in experience sampling studies. The results of the current study could significantly assist event companies to more effectively allocate their resources when designing and planning event programs to enhance event attendees’ experiences.

\section{Literature review}

\subsection{Appraisal of customer experience and associated emotions}

Customer experience is multidimensional (e.g., Gentile, Spiller, \& Noci, 2007; Palmer, 2010; Verhoef et al., 2009). Gentile et al. (2007) propose that customer experience can include spiritual, sensorial, physical, rational, and emotional dimensions. Verleye (2015) extends the literature by developing a multidimensional experience scale to measure overall experience, including hedonic, cognitive, social, personal, pragmatic, and economic experience dimensions. Their results suggest that customers appraise experience dimensions differently on the basis of what types of experiences they expect and then evaluate overall experience depending on congruence between what they encounter in situ and expected experience dimensions. That is, a higher congruence level between real-time experiences and individuals’ expected experience dimensions positively impacts their overall assessment, whereas lower congruence level implies a negative impact on overall experience.

Appraisal theory recognizes that individuals can have different emotional responses to an event owing to an individual's subjective evaluations of the event and proposes a range of dimensions as determinants of emotions, such as goal relevance, goal congruence, coping potential and future expectancy (Roseman et al., 1990). The current 
study only focuses on one key appraisal dimension - goal congruence - relevant in differentiating between positive and negative emotions. Goal congruence, which is the match between an individual's goals and real-time experiences, is an important underlying contributor to emotions (Roseman et al., 1990). According to Smith and Ellsworth (1985), the appraisal of congruence determines the valence of emotional responses. That is, events appraised at a higher congruence level are associated with positive emotions, whereas events appraised at a lower congruence level create more negative emotions.

Building upon the principles of appraisal theory, some researchers (e.g., Soscia, 2007) have investigated the relationship between goal congruence and positive/negative emotions. For instance, Nyer (1997) demonstrates that appraisals determine positive/negative emotions such as joy and anger. In another study, Hosany (2011) examines the determinants of tourists' emotional responses in the context of tourist destinations. The results demonstrate that goal congruence is a key determinant of emotions such as joy and inspiration. However, most previous research (e.g., Hosany, 2011) regards goal congruence as a unidimensional construct. Nevertheless, it can be argued that experience comprises many facets and people tend to evaluate their overall experience depending on the congruence between the multiple experiences encountered in situ and any associated personal goals (Verleye, 2015). Therefore, the congruence appraisals of different experience dimensions (such as cognitive, sensory, social) may vary in predictive power for emotional responses. Therefore, the following hypotheses are proposed: 
Hypothesis 1: The greater the congruence between the customer's experience appraisal dimensions and the person's goals, the stronger the person's positive emotional responses.

Hypothesis 1a: The less the congruence between the customer's experience appraisal dimensions and the person's goals, the stronger the person's negative emotional responses.

Hypothesis 2: Customer experience appraisal dimensions will differentially predict positive emotional responses.

Hypothesis 2a: Customer experience appraisal dimensions will differentially predict negative emotional responses.

\subsection{Appraisal of customer experience and overall assessment}

The customer experience literature (e.g., Kim, Suh, \& Eves, 2010; Wijaya, King, Nguyen, \& Morrison, 2013) recognizes the importance of key outcome variables such as customer satisfaction and behavioral intentions (e.g., intention to recommend and intention for repeat visit). Thus, our research also adopts these variables as an overall assessment of consumer sentiment and behaviors. As emotional responses influence customer satisfaction and various customer behaviors (e.g., Dalakas, 2006; Hosany \& Prayag, 2013), understanding the relationship between appraisals of different experience dimensions and associated emotional responses along the experience journey is very important. Given that emotions have been shown by prior studies (e.g., Hosany \& Prayag, 2013) to have a significant influence on customer satisfaction and various consumer behaviors, it is not surprising that the ratings of satisfaction and consumer behaviors are likely to be related to goal congruence appraisals. However, few empirical studies have 
examined the relationship between appraisals and customer satisfaction and customer behaviors. Nyer (1997) demonstrates that appraisals determine satisfaction and also affect post-consumption behaviors such as word-of-mouth intention. Soscia (2007) further establishes that congruence appraisals predict word of mouth and repurchase intention. However, most studies (e.g., Soscia, 2007) use an overall evaluation measure that may overlook the different predictive power of specific experience appraisal dimensions. Therefore, it is proposed:

Hypothesis 3: As customer experience appraisal dimensions increase in congruence with the person's goals, the ratings of customer satisfaction, intention to recommend, and intention for repeat visit will be higher.

Hypothesis 3a: Customer experience appraisal dimensions will differentially predict customer satisfaction, intention to recommend, and intention for repeat visit.

\subsection{Measuring appraisals and emotions in real time}

As customer experience is subjective, varies over time (Cutler, Carmichael, \& Doherty, 2014; Hormuth, 1986), and connects closely to goal congruence (Kuppens, Champagne, \& Tuerlinckx, 2012), real-time capture of all changes in appraisals and emotions is essential. Nearly all of the previous appraisal research (e.g., Hosany, 2011) relies on retrospective techniques such as surveys - an approach that has limitations in capturing the dynamic aspects of a customer's cognitive evaluations throughout the experience. Further, emotions are transitory, fluctuating from moment to moment. However, most previous emotion research (e.g., Hosany \& Gilbert, 2010) has captured individuals' emotions at one moment in time, which ignores the variability of emotions during the experience journey. Therefore, being able to identify customers' emotions at a 
given point in time as well as being able to measure experiences and emotions at different time points is important (Coghlan \& Pearce, 2010; Dubé \& Morgan, 1998). Thus, the final hypothesis is proposed:

Hypothesis 4: Customers’ emotional responses will vary over time.

2.4. The use of experience based sampling to measure appraisals and emotions in real time

One way to gain insight to people's appraisals and emotions in a natural context is through experience based sampling (EBS). This method is able to capture how people think, feel, and behave in "real time” (Hektner, Schmidt, \& Csikszentmihalyi, 2007), which offers unique insights into the momentary fluctuations associated with a customer's experience journey. An EBS approach has been adopted in psychology (Scollon, Prieto, \& Diener, 2003) to gain insights to the underlying factors that elicit behavior. The advantage of EBS is that it reduces recall biases associated with survey research methods as the time lag between actual experiences and responding to questions is usually quite short (Scollon et al., 2003). This method provides insight to the momentary fluctuations in experience, feelings and behaviors close to the point of occurrence. By the very nature of EBS, small sample sizes of participants are common (Hektner et al., 2007; Schimmack, 2003). However, the sample of experiences may be quite high. This method is attempting to achieve depth in understanding experiences rather than breadth that might be achieved in large-scale surveys. The EBS approach has also been shown to exhibit a high degree of ecological validity as the measurement takes place in situ using real lived experiences and feelings. This increases the external validity of the method as data collected are based on experiences in a real setting. In addition, it is 
argued that EBS is high on internal validity compared to one-time surveys, as there is a reduction in any recall biases (Hektner et al., 2007).

While traditional paper and pencil diaries have been used in experience based sampling, the advent of technology such as smartphones has enabled researchers to collect data in the field from participants (Hofmann \& Patel, 2014). In particular, multiple smartphone apps have been developed to help for the collection of real time data in experience based sampling studies. The use of apps in experience based sampling has a number of advantages including being able to control the signal timing, check for compliance through tracking and minimize missing data through sending response reminders (Scollon et al., 2003). Smartphone apps vary in functionalities (for an overview, see Conner, 2015) but offer a researcher a tool for conducting experience based sampling research. For example, MetricWire (https://metricwire.com/), a specially designed mobile app, allows researchers to collect in-the-moment data from device users (study participants). The current study adopted an experience based sampling method and used MetricWire as outlined in the method section.

\section{Method}

\subsection{Event context}

This study seeks to understand customer experiences using the context of a national food and wine event. This event was purposively chosen as it is a large annual food and wine event held indoors, and runs over a three-day weekend from Friday to Sunday. All participants arrive in the morning and attend the event for the full day. The event comprises many activities, including food and wine displays, celebrity chef demonstrations, cooking classes, coffee-making classes, and wine-tasting master classes, 
and offers some chill-out lounges and entertaining leisure activities (e.g., croquet). This broad offering allows for the capture and comparison of many experiences across the entire event period. Thus, while one event was the focus of the data collection, the event was large and provided many different experiences to occur.

\subsection{Participants}

A purposive sampling approach was undertaken and to be eligible for this study, participants needed to be a day-ticket holder for the event or to state a willingness to attend the event. They also had to be in attendance at all three in situ measurement times. The sample comprises 51 adults who attended the event (14 males and 37 females). The event organizer supplied 11 of these participants and direct recruitment resulted in 40 others. Respondents are between 18-65 years old, with most falling into the range of 2554 years old, which is reflective of the event's target market.

\subsection{Measures}

\subsubsection{Appraisal dimensions}

The survey included questions assessing appraisals of congruence between the person’s goals and experiences along five dimensions:

1. Bonding with family and friends

2. Discovering new trends about food and wine

3. Having fun

4. Interacting with food and wine experts

5. Having a positive sensory (e.g., smells, tastes) experience

These dimensions are identified as most salient in two previous focus group research projects: one conducted by the event organizer and the other by the authors. The 
questions assessing congruence on these dimensions used a stem adapted from Hosany (2011) and Kuppens et al. (2012): "How did your recent experience contribute to achieving the goals you had in relation to (insert one appraisal dimension)?” [1= not at all to 5 = very much].

\subsubsection{Emotions}

Three emotion items (two positive and one negative) adapted from the emotion scale of Hosany and Gilbert (2010) measured joy, inspiration, and disappointment. Each is worded as: “To what extent did you feel a sense of (either joy, inspiration or disappointment was automatically inserted)?” [1= not at all to $5=$ very much $]$.

\subsubsection{Overall assessments}

The post-event data collection encompassed measures of overall satisfaction ( 1 = very dissatisfied to 5 = very satisfied $)$, likelihood to recommend the event to others $(1=$ very unlikely to 5 = very likely), and likelihood to return to the event the following year ( $1=$ very unlikely to 5 = very likely). Demographic information included gender, age, employment status, number of previous visits, and dining out habits.

\subsection{Procedure}

This study employs an experience-based sampling method (i.e., a multi-entry diary approach) using mobile technology (i.e., smartphones and tablets) and an app (MetricWire) to measure people’s experiences in real time in the context of a food and wine event. Participants are recruited through two sources: (1) the event organizer’s participant database, and (2) the authors' university research volunteer recruitment system. All participants received an invitation email. Following registration in the study, participants downloaded a free app, MetricWire (https://metricwire.com/), and installed it 
on their devices to complete the study. Each participant received instructions in the use of the app, and training that required participants to complete two dummy questions to become familiar with process.

On the day at the event, participants completed the full set of appraisal and emotions items at three times - 11:00,12:30, and 14:00. Later the same day, at 20:00, to examine participants' overall evaluations after the event, the researchers sent participants the postevent survey, also through the MetricWire app, which included questions about overall satisfaction, intention to recommend, and intention to make a repeat visitation.

An interval-contingent sampling approach was selected based on logistical considerations and reviewing previous literature (e.g., Scollon et al., 2003; Uy, Foo, \& Aguinis, 2010). As the data collection context was a food and wine event held indoors, the researchers had to consider several key factors: hours of opening, number of sample points required, event factors, such as noise, respondent burden (interruptions), and retention. Based on advice from the event organizers, the main period of attendance was between 10:30am and 3pm. As we determined the need for a minimum of three in situ samples for each person, it was decided to use a 1.5 hour interval and commence at 11am (ensuring participants had arrived) and complete the final one at 2pm (before participants left the venue).

All participants who completed the study qualified to enter a prize draw to win one of six shopping vouchers (valued at $\$ 50$ each) plus a bonus prize draw for one of two restaurant vouchers (valued at \$100 each). People recruited through the university received free tickets to the event. The researchers' university gave ethical approval to 
conduct the study and the event organizer also gave permission to conduct the research at the event.

\section{Results}

\subsection{Sample profile}

Over $70 \%$ of the participants are females. Over $90 \%$ of participants are between 25-64 years old, and over 50\% work full-time and dine out $1-3$ times a week. Of the 51 participants, 32 attended this event for the first time and 35 attended with their family or partner. Two respondents failed to complete the survey at time three (T3). Their data are therefore not part of the inferential statistics. Preliminary tests were conducted to investigate if any differences occurred on the key independent variables or dependent variables by new versus repeat attendees. No significant differences were found and hypothesis testing was then undertaken.

\subsection{Relationship between appraisal dimensions and emotions}

To examine the effect of five appraisal dimensions on three emotions at each time interval (Hypothesis 1 and Hypothesis 1a), the researchers ran correlation tests (see Table 1). Results reveal significant correlations between all five appraisal dimensions and the sense of joy as well as the sense of inspiration at T1. At T2, results show significant correlations between four appraisal dimensions (i.e., bonding, discovering, having fun, and having sensory experiences) and two emotions (i.e., joy and inspiration). At T3, significant correlations occur between three appraisal dimensions (i.e., bonding, having fun, and sensory experiences) and the sense of joy, while four appraisal dimensions (i.e., bonding, discovering, having fun and sensory experiences) are significantly correlated 
with the sense of inspiration. Therefore, results fully support Hypothesis 1 at T1 and give conditional support at T2 and T3.

With respect to the sense of disappointment, results reveal significant negative correlations between four appraisal dimensions (i.e., bonding, discovering, having fun, and sensory experiences) and disappointment at T1, but show no significant correlation between the five appraisal dimensions and the sense of disappointment at T2 or T3.

Therefore, Hypothesis 1a gains conditional acceptance at T1. In addition, the mean scores for disappointment are 1.4, 1.2 and 1.1 (see Table 1 ), showing virtually no disappointment at any time point. As results show no discernable levels of disappointment or significant correlations between the appraisal dimensions and disappointment at T2 or T3, the researchers conducted no further inferential statistical analysis for disappointment (resulting in rejection of Hypothesis 2a).

\section{Table 1}

Means, standard deviations, and correlation matrix among variables for each time interval $(N=51)$.

\begin{tabular}{|c|c|c|c|c|c|c|c|c|c|c|c|}
\hline & Variables & M & SD & 1 & 2 & 3 & 4 & 5 & 6 & 7 & 8 \\
\hline \multirow[t]{8}{*}{$\mathrm{T} 1$} & 1. Bonding & 3.7 & 1.09 & 1.00 & & & & & & & \\
\hline & 2. Discovering & 3.2 & 1.08 & $.57^{* *}$ & 1.00 & & & & & & \\
\hline & 3. Having fun & 3.8 & 1.08 & $.68^{* *}$ & $.59^{* *}$ & 1.00 & & & & & \\
\hline & 4. Interacting & 3.4 & 1.29 & $.39^{* *}$ & $.61^{* *}$ & $.50^{* *}$ & 1.00 & & & & \\
\hline & 5. Sensory experience & 3.1 & 1.14 & $.48^{* *}$ & $.67^{* *}$ & $.49^{* *}$ & $.33^{* *}$ & 1.00 & & & \\
\hline & 6. Joy & 3.6 & .99 & $.68^{* *}$ & $.52^{* *}$ & $.69^{* *}$ & $.36^{*}$ & $.52^{* *}$ & 1.00 & & \\
\hline & 7. Inspiration & 3.3 & 1.06 & $.61^{* *}$ & $.55^{* *}$ & $.59^{* *}$ & $.38^{* *}$ & $.61^{* *}$ & $.70^{* *}$ & 1.00 & \\
\hline & 8. Disappointment & 1.4 & .72 & $-.45^{* *}$ & $-.36^{* *}$ & $-.30^{*}$ & -.15 & $-.36^{* *}$ & $-.43^{* *}$ & $-.31^{*}$ & 1.00 \\
\hline \multirow[t]{8}{*}{$\mathrm{T} 2$} & 1. Bonding & 4.1 & .81 & 1.00 & & & & & & & \\
\hline & 2. Discovering & 3.9 & 1.11 & $.47^{* *}$ & 1.00 & & & & & & \\
\hline & 3. Having fun & 4.3 & .74 & $.33^{*}$ & .23 & 1.00 & & & & & \\
\hline & 4. Interacting & 3.8 & 1.34 & .25 & .15 & $.57^{* *}$ & 1.00 & & & & \\
\hline & 5. Sensory experience & 3.9 & 1.01 & $.49^{* *}$ & $.62^{* *}$ & .27 & .08 & 1.00 & & & \\
\hline & 6. Joy & 4.1 & .77 & $.41^{* *}$ & $.28^{*}$ & $.46^{* *}$ & .22 & $.52^{* *}$ & 1.00 & & \\
\hline & 7. Inspiration & 3.7 & 1.01 & $.49^{* *}$ & $.54^{* *}$ & $.45^{* *}$ & .21 & $.59^{* *}$ & $.52^{* *}$ & 1.00 & \\
\hline & 8. Disappointment & 1.2 & .64 & -.03 & -.01 & -.03 & .12 & .02 & -.01 & .11 & 1.00 \\
\hline \multirow[t]{5}{*}{ T3 } & 1. Bonding & 4.3 & .72 & 1.00 & & & & & & & \\
\hline & 2. Discovering & 3.7 & 1.07 & $.29^{*}$ & 1.00 & & & & & & \\
\hline & 3. Having fun & 4.3 & .80 & $.50^{* *}$ & .28 & 1.00 & & & & & \\
\hline & 4. Interacting & 4.0 & 1.15 & .14 & $41^{* *}$ & $.53^{* *}$ & 1.00 & & & & \\
\hline & 5. Sensory experience & 3.7 & 1.13 & $.39^{* *}$ & $.34^{*}$ & .21 & .12 & 1.00 & & & \\
\hline
\end{tabular}




\begin{tabular}{lcccccccccc} 
6. Joy & 4.2 & .76 & $.52^{* *}$ & .27 & $.57^{* *}$ & .27 & $.35^{*}$ & 1.00 & & \\
7. Inspiration & 3.6 & 1.00 & $.40^{* *}$ & $.44^{* *}$ & $.31^{*}$ & .22 & $.71^{* *}$ & $.50^{* *}$ & 1.00 & \\
8. Disappointment & 1.1 & .28 & -.14 & -.18 & -.12 & -.06 & -.05 & -.08 & -.17 & 1.00 \\
\hline
\end{tabular}

** Correlation is significant at the.01 level (two-tailed).

* Correlation is significant at the.05 level (two-tailed).

Next, multiple regression analysis tested whether the five appraisal dimensions differentially predict participants' ratings of joy and inspiration at T1, T2, and T3

(Hypothesis 2).

Table 2

Linear model of five appraisal dimension predictors of joy at T1, T2, and T3 $(N=51)$.

\begin{tabular}{llll}
\hline \hline & $\mathrm{T} 1$ & $\mathrm{~T} 2$ & $\mathrm{~T} 3$ \\
\cline { 2 - 4 } & $\beta^{\mathrm{a}}$ & $\beta^{\mathrm{b}}$ & $\beta^{\mathrm{c}}$ \\
\hline Bonding with family and friends & $.34^{*}$ & .17 & .25 \\
Discovering new trends about food and wine & -.02 & -.10 & .04 \\
Having fun & $.39^{*}$ & $.35^{*}$ & $.42^{*}$ \\
Interacting with food and wine experts & -.02 & -.04 & -.02 \\
Having a positive sensory experience & .19 & $.36^{*}$ & .15 \\
\hline \hline
\end{tabular}

a. $R^{2}=.58, F(5,45)=12.36, p<.05$

b. $R^{2}=.37, F(5,45)=5.20, p<.05$

c. $R^{2}=.42, F(5,45)=6.30, p<.05$

$* p<.05 .{ }^{* *} p<.01 .{ }^{* * *} p<.001$.

As Table 2 shows, results indicate that the five predictors explain $58 \%$ of the variance in joy at T1. "Bonding" and "having fun" significantly predict joy ratings. At T2, the five predictors explain 37\% of the variance. "Having fun" and "sensory experience" significantly predict joy ratings. At T3, the predictors explain $42 \%$ of the variance, with "having fun” significantly predicting joy ratings.

Similarly, multiple regression analysis tested whether the five appraisal dimensions differently predict participants' ratings of inspiration at T1, T2 and T3. Results appear in Table 3.

Table 3

Linear model of five appraisal dimension predictors of inspiration at T1, T2, and T3 ( $N=$ $51)$. 


\begin{tabular}{lccc}
\hline \hline & $\mathrm{T} 1$ & $\mathrm{~T} 2$ & $\mathrm{~T} 3$ \\
\cline { 2 - 4 } & $\beta^{\mathrm{a}}$ & $\beta^{\mathrm{b}}$ & $\beta^{\mathrm{c}}$ \\
\hline Bonding with family and friends & .29 & .15 & .07 \\
Discovering new trends about food and wine & .02 & .23 & .19 \\
Having fun & .19 & $.30^{*}$ & .09 \\
Interacting with food and wine experts & .06 & -.06 & .02 \\
Having a positive sensory experience & $.37^{*}$ & $.30^{*}$ & $.60^{* * *}$ \\
\hline \hline
\end{tabular}

a. $R^{2}=.53, F(5,45)=10.20, p<.05$

b. $R^{2}=.49, F(5,45)=8.71, p<.05$

c. $R^{2}=.56, F(5,45)=11.04, p<.05$

$* p<.05 .{ }^{* *} p<.01 .{ }^{* * *} p<.001$.

At T1, the five predictors explain 53\% of the variance in inspiration. "Sensory experience” significantly predicts inspiration ratings. At T2, the predictors explain $49 \%$ of the variance, with each of "having fun" and "sensory experience" significantly predicting inspiration ratings. At T3, the predictors explain 56\% of the variance. "Sensory experience" significantly predicts inspiration ratings. These results support Hypothesis 2 .

\subsection{Relationship between appraisal dimensions and overall assessment}

Overall assessments were collected after the event and were all positively evaluated: satisfaction $\mathrm{M}=4.5, \mathrm{SD}=.58$; intention to recommend $\mathrm{M}=4.4, \mathrm{SD}=.78$; intention to repeat visit $\mathrm{M}=4.0, \mathrm{SD}=1.02$. As Table 4 shows, the tests of Hypothesis 3 show that none of the five appraisal dimensions is significantly correlated with satisfaction, intention to recommend, or intention for repeat visitation at T1. At T2, "sensory experience" is positively correlated with satisfaction, intention to recommend, and intention for repeat visit, "having fun" is positively correlated with intention to recommend and intention for repeat visit, and "bonding” is positively correlated with intention to recommend. At T3, "having fun" is positively correlated with all three overall evaluations, "bonding" is positively correlated with satisfaction and intention to 
recommend, and "discovering” is positively correlated with intention to recommend.

Therefore, results lead to rejection of Hypothesis 3 at T1 and conditional acceptance at

$\mathrm{T} 2$ and $\mathrm{T} 3$.

\section{Table 4}

Correlations among variables for each time interval $(N=51)$.

\begin{tabular}{llccc}
\hline \hline Variables & Satisfaction & $\begin{array}{c}\text { Intention to } \\
\text { recommend }\end{array}$ & $\begin{array}{c}\text { Intention to } \\
\text { repeat visit }\end{array}$ \\
\hline T1 & 1. Bonding & .15 & .22 & .14 \\
2. Discovering & .05 & .11 & .11 \\
3. Having fun & .16 & .26 & .20 \\
4. Interacting & .14 & .13 & .17 \\
5. Sensory experience & .08 & .18 & .14 \\
\hline T2 & 1. Bonding & .15 & $.28^{*}$ & .12 \\
2. Discovering & .08 & .13 & .09 \\
3. Having fun & .22 & $.33^{*}$ & $.32^{*}$ \\
4. Interacting & .17 & .15 & .24 \\
5. Sensory experience & $.29^{*}$ & $.44^{* *}$ & $.35^{*}$ \\
\hline T3 1. Bonding & $.44^{* *}$ & $.35^{*}$ & .20 \\
2. Discovering & .19 & $.29^{*}$ & .23 \\
3. Having fun & $.40^{* *}$ & $.38^{* *}$ & $.32^{*}$ \\
4. Interacting & .16 & .07 & .00 \\
5. Sensory experience & .20 & .19 & $.30^{*}$ \\
\hline \hline
\end{tabular}

**Correlation is significant at the 0.01 level (two-tailed).

* Correlation is significant at the 0.05 level (two-tailed).

Next, multiple regression analysis tested whether the five appraisal dimensions significantly predict participants' ratings of satisfaction, intention to recommend, and intention for repeat visit at T2 and T3 (Hypothesis 3a). Table 5 presents the results.

\section{Table 5}

Linear model of five appraisal dimension predictors of satisfaction and intentions at T2 and T3 $(N=51)$.

\begin{tabular}{|c|c|c|c|c|c|c|}
\hline & \multicolumn{2}{|c|}{ Satisfaction } & \multicolumn{2}{|c|}{$\begin{array}{l}\text { Intention to } \\
\text { recommend }\end{array}$} & \multicolumn{2}{|c|}{$\begin{array}{l}\text { Intention to } \\
\text { repeat visit }\end{array}$} \\
\hline & $\mathrm{T} 2$ & T3 & $\mathrm{T} 2$ & T3 & $\mathrm{T} 2$ & T3 \\
\hline & $\beta^{\mathrm{a}}$ & $\beta^{\mathrm{b}}$ & $\beta^{\mathrm{c}}$ & $\beta^{\mathrm{d}}$ & $\beta^{\mathrm{e}}$ & $\beta^{\mathrm{f}}$ \\
\hline Bonding with family and friends & -.00 & .30 & .09 & .12 & -.11 & -.12 \\
\hline Discovering new trends about food and wine & -.19 & .05 & -.27 & .25 & -.22 & .20 \\
\hline Having fun & .10 & .25 & .23 & $.39^{*}$ & .20 & $.45^{*}$ \\
\hline
\end{tabular}




\begin{tabular}{lcc|cc|cc} 
Interacting with food and wine experts & .11 & -.04 & -.01 & -.26 & .15 & -.33 \\
Having a positive sensory experience & .37 & .01 & $.50^{* *}$ & .01 & $.48^{*}$ & .22 \\
\hline
\end{tabular}

a. $\quad R^{2}=.13, F(5,45)=1.39, p<.05$

b. $\quad R^{2}=.24, F(5,45)=2.68, p<.05$

c. $R^{2}=.28, F(5,45)=3.51, p<.05$

d. $R^{2}=.24, F(5,45)=2.76, p<.05$

e. $R^{2}=.23, F(5,45)=2.68, p<.05$

f. $R^{2}=.23, F(5,45)=2.57, p<.05$

${ }^{*} p<.05 .{ }^{* *} p<.01 .{ }^{* * *} p<.001$.

At T2, the set of predictors explain only $13 \%$ of the variance in satisfaction. At T3, the predictors explain $24 \%$ of the variance in satisfaction. However, none of the appraisal dimensions significantly predicts satisfaction ratings.

The predictors explain $28 \%$ of the variance in intention to recommend at T2. "Sensory experience” significantly predicts recommendation ratings. At T3, the predictors explain $24 \%$ of the variance in intention to recommend, with "having fun” the only significant predictor.

Turning to the prediction of repeat visit intention, the predictors explain $23 \%$ of the variance at T2. “Sensory experience” significantly predicts repeat visitation ratings. At T3, the predictors explain 23\% of the variance in repeat visitation intention, with "having fun” the sole significant predictor. Therefore, findings result in rejection of Hypothesis 3a for satisfaction ratings and conditional acceptance for ratings of intention to recommend and intention for repeat visitation. Of note are the relatively strong effects of sensory experience at $\mathrm{T} 2$ and having fun at $\mathrm{T} 3$.

\subsection{Emotional variation during the event}

To test Hypothesis 4, two separate one-way within-subjects (repeated measures) ANOVAs compared the effect of time on ratings of joy and inspiration (non-significant correlations at T2 and T3 led to no similar analysis involving disappointment). Table 6 
summarizes the results. Time had a significant effect for joy (Wilks’ lambda $=0.77, F(2$, $47)=7.01, p=.002, \eta^{2}=.23$ ), but no significant effect on inspiration (Wilks’ lambda $=$ 0.93, $\left.F(2,47)=1.79, p=.178, \eta^{2}=.07\right)$.

\section{Table 6}

Mean scores, standard deviations, and repeated-measures ANOVA results of emotion items $(N=51)$.

\begin{tabular}{lccccc}
\hline \hline Variables & $\mathrm{T} 1$ & $\mathrm{~T} 2$ & $\mathrm{~T} 3$ & F-value $^{\mathrm{a}}$ & Eta squared \\
\hline Joy & $3.6(.98)$ & $4.1(.78)$ & $4.2(.76)$ & $7.01^{*}$ & .23 \\
Inspiration & $3.3(1.05)$ & $3.6(1.01)$ & $3.6(1.00)$ & 1.79 & .07 \\
\hline \hline
\end{tabular}

a. $\quad{ }^{*} p<.05, F(2,47)=7.01$.

b. To rate their momentary feelings, individuals used a five-point Likert scale that ranged from $1=$ not at all to $3=$ moderate amount to $5=$ very much.

c. Standard deviations are in the parentheses.

Follow-up tests using three paired-sample t-tests made post hoc comparisons between times for the dependent variable of joy. Results indicate a significant difference in the scores for joy at T1 and T2 (t (50) $=-3.50, p=.001)$, and also a significant difference between the scores for joy at T1 and T3 (t (48) $=-3.71, p=.001)$. However, results show no significant difference between the scores at T2 and T3 (t $(48)=-0.68, p=.50)$.

These results suggest that duration of experience really does have an effect on an individual's sense of joy, with joy increasing from T1 to T2 and from T1 to T3, but not between T2 and T3. Therefore, results support acceptance of Hypothesis 4 for joy but lead to rejection for inspiration.

Table 7 summarizes the results of the tests of all hypotheses.

\section{Table 7}

Results of hypotheses tests.

\begin{tabular}{l|l}
\hline \hline Hypotheses & \multicolumn{1}{c}{ Results } \\
\hline $\begin{array}{l}\text { H1: The greater the congruence between the customer's } \\
\text { experience appraisal dimensions and the person's goals, } \\
\text { the stronger the person's positive emotional responses. }\end{array}$ & $\begin{array}{l}\text { Accepted at T1 and } \\
\text { conditionally accepted at T2 } \\
\text { and T3 }\end{array}$ \\
\hline $\begin{array}{l}\text { H1a: The less the congruence between the customer's } \\
\text { experience appraisal dimensions and the person's goals, } \\
\text { the stronger the person's negative emotional responses. }\end{array}$ & $\begin{array}{l}\text { Conditionally accepted at T1 } \\
\text { only }\end{array}$ \\
\hline
\end{tabular}




\begin{tabular}{l|l}
\hline $\begin{array}{l}\text { H2: Customer experience appraisal dimensions will } \\
\text { differentially predict positive emotional responses. }\end{array}$ & Accepted \\
\hline $\begin{array}{l}\text { H2a: Customer experience appraisal dimensions will } \\
\text { differentially predict negative emotional responses. }\end{array}$ & Rejected \\
\hline $\begin{array}{l}\text { H3: As customer experience appraisal dimensions } \\
\text { increase in congruence with the person's goals, the } \\
\text { ratings of customer satisfaction, intention to recommend, } \\
\text { and intention for repeat visit will be higher. }\end{array}$ & $\begin{array}{l}\text { Rejected at T1, and } \\
\text { conditionally accepted at T2 } \\
\text { and T3 }\end{array}$ \\
\hline $\begin{array}{l}\text { H3a: Customer experience appraisal dimensions will } \\
\text { differentially predict customer satisfaction, intention to } \\
\text { recommend, and intention for repeat visit. }\end{array}$ & $\begin{array}{l}\text { Rejected for satisfaction and } \\
\text { conditionally accepted for } \\
\text { intention to recommend and } \\
\text { intention for repeat visit }\end{array}$ \\
\hline H4: Customers' emotional responses will vary over time. & $\begin{array}{l}\text { Accepted for joy; rejected for } \\
\text { inspiration. }\end{array}$ \\
\hline
\end{tabular}

\section{Discussion and conclusions}

The present study employs experience based sampling to investigate how individuals at an event make specific appraisals across time and how these appraisals affect in situ emotions and overall evaluations of the event. Importantly, the adoption of an EBS study facilitates the ability to test how emotions vary throughout the event. The results suggest that at different points in time, the five appraisal dimensions have impacts in explaining the variance in joy and inspiration, although the analysis finds no significance between the appraisal dimensions and disappointment. In terms of the relationship between appraisals and overall assessments, none of the appraisal dimensions significantly predicts satisfaction ratings, although the appraisal dimensions have impact in explaining the variance in intention to recommend and intention for repeat visit at T2 and T3. In 
addition, the results also suggest that over time, being at the event heightens the individual's sense of joy but not that of inspiration.

This study makes a number of important contributions. First, drawing on the principles of appraisal theory, this study extends the understanding of the theory by providing information about how appraisals of specific experience dimensions affect emotional responses. Second, by incorporating experience-based sampling the study reveals the fluctuations of individuals' appraisals and emotional responses across time, as well as the time based connections between appraisals and emotions. Third, findings show that the later stage of customer experience appraisals has greater impact on customers' overall evaluations.

Appraisal theory (e.g., Roseman et al., 1990) proposes that a customer’s appraisal of the congruence between the experience and prior goals is a key determinant of the individual's emotional responses. In particular, goal congruence elicits positive emotions and goal incongruence elicits negative emotions. Taking the multidimensional nature of customer experience into account, this study extends the theory by investigating how individuals evaluate different experience dimensions depending on the appraisals of what expected goals are met and how appraisals of specific dimensions of customer experience affect customers' emotional responses and overall assessments. As this investigation shows, the appraisal of "having fun" consistently predicts the variance in joy levels irrespective of time, while the appraisal of "having a positive sensory experience" consistently explains the variance in the ratings of inspiration at three sampling points. Interestingly, the analysis identifies no association between the five appraisal dimensions and the sense of disappointment. This finding could result from the hedonic nature of this 
type of event experience: attending a food and wine event is a form of relaxation in which attendees anticipate having enjoyable, inspiring, and memorable experiences (see also Hosany \& Gilbert, 2010). Also, the extremely low level of disappointment might explain the finding, as there is very little variance in this measure (most participants indicated they are not at all disappointed).

Previous research on emotions (e.g., Lin et al., 2014; Nawijn, Mitas, Lin, \& Kerstetter, 2013) acknowledges that individuals’ emotions vary during the experience journey and suggests the importance of measuring evolving stages of emotions throughout the course of an experience. In previous studies, Lin et al. (2014) and Nawijn et al. (2013) demonstrate that individuals' emotions fluctuate during a vacation and particularly the positive emotions are rated higher in the middle rather than the end of the trip. Using experience-based sampling, the present results also illustrate that participants' emotions fluctuate during the one-day period. However, the results of this study indicate that participants experience significant changes in the levels of joy, which increase from T1 to T2 and also from T1 to T3. When customers first arrive at the venue, the level of joy is relatively low. As the customer has more experiences at the event, they report having more fun and higher levels of joy. The study identifies no significant effect of time on the sense of inspiration, although there are small increases in variable over time.

Studies of service design (e.g., Stickdorn \& Schneider, 2009; Zomerdijk \& Voss, 2010) and service marketing (e.g., Verhoef, Antonides, \& De Hoog, 2004) suggest that orchestrating the sequence, progression, and duration of service encounters enhances customer experience by engaging customers emotionally and contributing to customer satisfaction. The findings of the present study indicate that none of the appraisal 
dimensions significantly predicts satisfaction ratings, which confirms the complex nature of customer satisfaction that previous studies have identified (e.g., Del Río-Lanza, Vázquez-Casielles, \& Díaz-Martín, 2009; Pullman \& Gross, 2004; Uriely, 2005): customer satisfaction is not simply based on cognitive evaluation but instead is a complex affective response. The appraisal of "having a positive sensory experience" at T2 predicts ratings of intention to recommend and intention for repeat visitation, and the appraisal of "having fun” at T3 explains the variance in ratings of intention to recommend and intention for repeat visitation. Thus, the appraisals fluctuate and have different impacts at different points in time (Birenboim, Reinau, Shoval, \& Harder, 2015; Lee \& Shafer, 2002; Mathes, 1982). This findings underscores the importance of using an experiencesampling research method, because reliance on a single post-event survey would unlikely have identified the important role played by positive sensory experiences midway through the event (see also Quinlan Cutler, Doherty, \& Carmichael, 2016). These results also imply that customers may not attach equal significance to every single moment of an experience. Rather, customer experience appraisals at mid and later points carry greater weight in customers' overall evaluations than do appraisals of initial (T1) experiences. The findings have a number of managerial implications. First, this study shows the importance of understanding customers' goals. Results identify that customers appraise specific experience dimensions differently. For example, two customers attending the food and wine event may have different goals: one may be interested in spending time in a cooking class and learning new recipes from the experts whereas the second could have the goal of enjoying a fun day with friends, eating and drinking together. Both attendees are likely to evaluate their experiences positively if their actual experiences match their 
goals, demonstrating that goal congruence is important in ensuring positive customer experience.

Second, results also demonstrate that appraisals of specific experience dimensions are key determinants of positive emotional responses such as joy and inspiration. In the above example of two customers seeking different experiences at the same event, the first customer who is interested in learning cooking skills and recipes is likely to experience the sense of inspiration during the interactions with food experts while the second who is more inclined to relax with friends is likely to experience the sense of joy through all the chatting, eating and drinking. Therefore, service providers should strive to understand customers' specific goals so as to create desired experiences for customers, which could consistently elicit positive emotional responses. In addition, results indicate that appraisals of later experiences of an event have a stronger impact on customer's overall evaluations than do earlier experience appraisals. This finding can be very useful in the temporal design of service experiences to influence customers' perceptions of the service delivery process and their post-consumption evaluations.

\section{Limitations and future research}

Employing the real-time experience-sampling technique, this study examines the association between appraisals and emotions in situ together with post-situation overall assessments of satisfaction, intention to recommend, and intention to repeat the visitation. Of course, like all research, this study entails strengths but also some limitations, which offer avenues for future research.

First, the method requires a certain level of commitment from participants (time) and the researchers (financial support). Therefore, this study examines only one context (a 
food and wine event), and future research could be conducted in other event contexts. Second, the experience-based sampling method requires participants to report their appraisals and feelings while attending the event. To minimize intrusion into participants' real experiences, this study relied on a very short survey employing single items for appraisals, emotions, and overall assessments. While accommodating three sampling points in the one-day event experience is difficult, future studies could consider the possibility of increasing the number of in situ data collection points - a step that offers the opportunity for high-level data analysis, such as multilevel modeling analysis, which might bring more insights. In addition, by having more time points for collecting information about experiences, it is possible to construct studies that can test the role of experience strength (e.g. peak type experience) as a predictor of overall evaluations. For instance, Quan and Wang (2004) propose that supporting and peak experiences can contribute to customer satisfaction. Future research can use the EBS approach to differentiate supporting and peak experiences as well as their subsequent impact on evaluations. Furthermore, variables such as intention for repeat visit should be treated with caution as people may seek new experiences and the effect on this variable may be less evident than other consumer behavior variables. Finally, other theoretical frameworks could be applied and investigated such as perceived value (e.g., Walls, 2013; Walls, Okumus, Wang, \& Kwun, 2011) or Service Dominant Logic (SDL) (e.g., Vargo \& Lusch, 2008). Applying these theories in an experience based sampling study could be potentially insightful for future research. However, overall, despite its limitations this study provides a foundation for a better and deeper understanding of the customer 
experience, by adding to previous research that has used more retrospective techniques such as interviews and surveys. 


\section{References}

Birenboim, A., Reinau, K. H., Shoval, N., \& Harder, H. (2015). High-resolution measurement and analysis of visitor experiences in time and space: The case of Aalborg Zoo in Denmark. The Professional Geographer, 67(4), 620-629.

Coghlan, A., \& Pearce, P. (2010). Tracking affective components of satisfaction. Tourism and Hospitality Research, 10(1), 42-58.

Conner, T. S. (2015). Experience sampling and ecological momentary assessment with mobile phones. http://www.otago.ac.nz/psychology/otago047475.pdf

Cutler, S. Q., Carmichael, B., \& Doherty, S. (2014). The Inca Trail experience: Does the journey matter? Annals of Tourism Research, 45, 152-166.

Dalakas, V. (2006). The effect of cognitive appraisals on emotional responses during service encounters. Services Marketing Quarterly, 27(1), 23-41.

Del Río-Lanza, A. B., Vázquez-Casielles, R., \& Díaz-Martín, A. M. (2009). Satisfaction with service recovery: Perceived justice and emotional responses. Journal of Business Research, 62(8), 775-781.

Dubé, L., \& Morgan, M. S. (1998). Capturing the dynamics of in-process consumption emotions and satisfaction in extended service transactions. International Journal of Research in Marketing, 15(4), 309-320.

Gentile, C., Spiller, N., \& Noci, G. (2007). How to sustain the customer experience: An overview of experience components that co-create value with the customer. European Management Journal, 25(5), 395-410.

Hektner, J. M., Schmidt, J. A., \& Csikszentmihalyi, M. (2007). Experience sampling method: Measuring the quality of everyday life. USA: Sage. 
Hofmann, W., \& Patel, P. V. (2014). SurveySignal: A convenient solution for experience sampling research using participants’ own smartphones. Social Science Computer Review, 1-19.

Hormuth, S. E. (1986). The sampling of experiences in situ. Journal of Personality, 54(1), 262-293.

Hosany, S. (2011). Appraisal determinants of tourist emotional responses. Journal of Travel Research, 51(3), 1-12.

Hosany, S., \& Gilbert, D. (2010). Measuring tourists’ emotional experiences toward hedonic holiday destinations. Journal of Travel Research, 49(4), 513-526.

Hosany, S., \& Prayag, G. (2013). Patterns of tourists' emotional responses, satisfaction, and intention to recommend. Journal of Business Research, 66(6), 730-737.

Hosany, S., \& Witham, M. (2009). Dimensions of cruisers' experiences, satisfaction, and intention to recommend. Journal of Travel Research, 49(3), 351-364.

Kim, Y. G., Suh, B. W., \& Eves, A. (2010). The relationships between food-related personality traits, satisfaction, and loyalty among visitors attending food events and festivals. International Journal of Hospitality Management, 29(2), 216-226.

Kuppens, P., Champagne, D., \& Tuerlinckx, F. (2012). The dynamic interplay between appraisal and core affect in daily life. Frontiers in Psychology, 3(380), 1-8.

Lee, B., \& Shafer, C. S. (2002). The dynamic nature of leisure experience: An application of affect control theory. Journal of Leisure Research, 34(3), 290.

Lin, Y., Kerstetter, D., Nawijn, J., \& Mitas, O. (2014). Changes in emotions and their interactions with personality in a vacation context. Tourism Management, 40, 416-424. 
Mathes, E. W. (1982). Peak experience tendencies scale development and theory testing. Journal of Humanistic Psychology, 22(3), 92-108.

Meyer, C., \& Schwager, A. (2007). Understanding customer experience. Harvard Business Review, 85(2), 116-127.

Mosteller, J., Donthu, N., \& Eroglu, S. (2014). The fluent online shopping experience. Journal of Business Research, 67(11), 2486-2493.

Nawijn, J., Mitas, O., Lin, Y., \& Kerstetter, D. (2013). How do we feel on vacation? A closer look at how emotions change over the course of a trip. Journal of Travel Research, 52(2), 265-274.

Nyer, P. U. (1997). A study of the relationships between cognitive appraisals and consumption emotions. Journal of the Academy of Marketing Science, 25(4), 296304.

Palmer, A. (2010). Customer experience management: A critical review of an emerging idea. Journal of Services Marketing, 24(3), 196-208.

Pullman, M. E., \& Gross, M. A. (2004). Ability of experience design elements to elicit emotions and loyalty behaviors. Decision Sciences, 35(3), 551-578.

Quan, S., \& Wang, N. (2004). Towards a structural model of the tourist experience: An illustration from food experiences in tourism. Tourism Management, 25(3), 297305.

Quinlan Cutler, S., Doherty, S., \& Carmichael, B. (2016). The experience sampling method: Examining its use and potential in tourist experience research. Current Issues in Tourism, 1-23. 
Roseman, I. J., Spindel, M. S., \& Jose, P. E. (1990). Appraisals of emotion-eliciting events: Testing a theory of discrete emotions. Journal of Personality and Social Psychology, 59(5), 899.

Schimmack, U. (2003). Affect measurement in experience sampling research. Journal of Happiness Studies, 4(1), 79-106.

Scollon, C. N., Prieto, C.-K., \& Diener, E. (2003). Experience sampling: Promises and pitfalls, strength and weaknesses. Journal of Happiness Studies, 4(1), 5-14.

Smith, C. A., \& Ellsworth, P. C. (1985). Patterns of cognitive appraisal in emotion. Journal of Personality and Social Psychology, 48(4), 813-838.

Soscia, I. (2007). Gratitude, delight, or guilt: The role of consumers' emotions in predicting postconsumption behaviors. Psychology \& Marketing, 24(10), 871894.

Stickdorn, M., \& Schneider, J. (2009). myServiceFellow: Gaining genuine customer insights. Paper presented at the Dethinking Service, Dethinking Design: First Nordic Conference on Service Design and Service Innovation, Oslo School of Architecture and Design, Oslo, Norway.

Uriely, N. (2005). The tourist experience: Conceptual developments. Annals of Tourism Research, 32(1), 199-216.

Uy, M. A., Foo, M.-D., \& Aguinis, H. (2010). Using experience sampling methodology to advance entrepreneurship theory and research. Organizational Research Methods, 13(1), 31-54.

Vargo, S. L., \& Lusch, R. F. (2008). Service-dominant logic: Continuing the evolution. Journal of the Academy of Marketing Science, 36(1), 1-10. 
Verhoef, P. C., Antonides, G., \& De Hoog, A. N. (2004). Service encounters as a sequence of events: The importance of peak experiences. Journal of Service Research, 7(1), 53-64.

Verhoef, P. C., Lemon, K. N., Parasuraman, A., Roggeveen, A., Tsiros, M., \& Schlesinger, L. A. (2009). Customer experience creation: Determinants, dynamics and management strategies. Journal of Retailing, 85(1), 31-41.

Verleye, K. (2015). The co-creation experience from the customer perspective: Its measurement and determinants. Journal of Service Management, 26(2), 321-342.

Walls, A. R. (2013). A cross-sectional examination of hotel consumer experience and relative effects on consumer values. International Journal of Hospitality Management, 32, 179-192.

Walls, A. R., Okumus, F., Wang, Y. R., \& Kwun, D. J.-W. (2011). An epistemological view of consumer experiences. International Journal of Hospitality Management, 30(1), 10-21.

Wijaya, S., King, B., Nguyen, T.-H., \& Morrison, A. (2013). International visitor dining experiences: A conceptual framework. Journal of Hospitality and Tourism Management, 20, 34-42.

Zomerdijk, L. G., \& Voss, C. A. (2010). Service design for experience-centric services. Journal of Service Research, 13(1), 67-82. 